\title{
Prediction of Single Dose Methotrexate Success in Ectopic Pregnancy Treatment
}

\author{
Derna Aslan Çetin ${ }^{1}$, (D) Begüm Aydoğan Mathyk²
}

1 University of Health Sciences, Kanuni Sultan Süleyman Training and Resarch Hospital, Clinic of Obstetrics and Gynecology, Istanbul, Turkey 2University of North Carolina Faculty of Medicine, Department of Obstetrics and Gynecology, Division of Reproductive Endocrinology and Infertility, Chapel Hill, North Carolina, USA

\section{Abstract}

Objective: To investigate the efficacy of single-dose methotrexate treatment and the factors affecting its success in the treatment of ectopic pregnancy.

Methods: Ectopic pregnancy cases treated with single dose methotrexate treatment between January 2013 and December 2017 were compared as successful and unsuccessful. Demographic characteristics of patients, ectopic mass size, beta human chorionic gonodotropin ( $\beta$-hCG) values at the beginning of treatment and at $4^{\text {th }}$ and $7^{\text {th }}$ days were evaluated.

Results: A total of 462 patients, who underwent single dose methotrexate treatment as initial ectopic pregnancy treatment, were included in the study. Single dose methotrexate treatment was successful in 350 patients (75.8\%) and failed in 112 patients (24.2\%). Serum $\beta$-hCG levels on the day of methotrexate administration, $\beta$-hCG values at $4^{\text {th }}$ day and at $7^{\text {th }}$ day, and ectopic mass size were significantly higher in the failed group $(p<0.001)$.

Conclusion: There are a number of factors affecting the success of single dose methotrexate treatment in ectopic pregnancy in hemodynamically stable patients. The most important of these are ectopic mass size and initial $\beta$-hCG value.

Keywords: Ectopic pregnancy, single dose, methotrexate

\section{INTRODUCTION}

Ectopic pregnancy is the implantation of a blastocyst somewhere other than the endometrial cavity (1). It is one of the most important causes of mortality and morbidity in the first trimester (2). The incidence in all pregnancies varies between 0.5 and $2 \%$ (1). The incidence of ectopic pregnancy has increased in recent years due to the increase in the frequency of previous pelvic infections, increased use of intrauterine devices, increased incidence of pelvic inflammatory disease, and increased pregnancy assisted reproductive techniques (3). Early diagnosis and treatment of ectopic pregnancies can be made thanks to the fact that beta human chorionic gonodotropin ( $\beta$-hCG) values can be routinely examined and transvaginal ultrasonography becomes widespread (4). Medical treatment, surgical treatment or wait and see method are the treatment options. Patients can benefit from medical treatment when the diagnosis can be made while the patients are hemodynamically stable and before rupture $(5,6)$. Medical treatment has many advantages over other treatments; these include less tubal damage, lower cost and preservation of fertility. Single dose methotrexate treatment is an effective and safe medical treatment and success rates vary between $64 \%$ and $94 \%$ (7). Methotrexate dose may be repeated or surgery may be performed in patients who fail single dose treatment (8-11). In this study, we aimed to compare successful and unsuccessful patients who underwent single-dose methotrexate treatment for ectopic pregnancy in our hospital and to determine the factors affecting success.

\section{METHODS}

Our study is a retrospective case-control study involving patients who were treated for ectopic pregnancy in the Clinic of Obstetrics and Gynecology, Kanuni Sultan Süleyman Training 
and Research Hospital between January 2013 and December 2017. After the approval of the ethics committee, the records of 461 patients who were hospitalized with ectopic pregnancy and who received single-dose methotrexate treatment were evaluated retrospectively. Diagnosis of ectopic pregnancy was made when serum $\beta$-hCG level $>1500 \mathrm{mIU} / \mathrm{mL}$ and transvaginal ultrasonography failed to show intrauterine gestational sac or succeeded to show ectopic focus, or less than $60 \%$ increase in $\beta$-hCG levels in 48 hours or plateau when $\beta$-hCG level $<1500$ mIU/ $\mathrm{mL}$, or absence of chorionic villus in pathological examination after dilatation curettage and/or patency of elevated $\beta$-hCG values despite curettage. The definite contraindications of methotrexate treatment were unstable hemodynamics, active hepatic or renal disease, and relative contraindications were $\beta$-hCG $>10.000 \mathrm{mIU} / \mathrm{mL}$ and fetal cardiac activity. A single dose of $50 \mathrm{mg} / \mathrm{m}^{2}$ methotrexate was administered intramuscularly. Treatment was considered successful if $\beta$-hCG levels decreased by more than $15 \%$ between the $4^{\text {th }}$ and $7^{\text {th }}$ days of treatment and the serum $\beta$-hCG levels decreased below $5 \mathrm{mIU} / \mathrm{mL}$ at weekly follow-up. Patients who had an increase in serum $\beta$-hCG concentration, less than $15 \%$ decrease on the $7^{\text {th }}$ day of treatment or rupture were treated with a second dose of methotrexate or surgical treatment. Treatment was considered to be unsuccessful in patients who required surgery or second dose methotrexate.

\section{Statistical Analysis}

Statistical analyzes were performed using the Statistical Package for Social Sciences 20.0 (SPSS Inc., Chicago, IL, USA) program. The distribution of the data was evaluated by Kolmogorov-Smirnov test. Descriptive statistical methods (mean, standard deviation) as well as independent t-test were used for the comparison of the normally distributed data. Results were evaluated at $p<0.05$ level of significance. In ROC analysis, serum $\beta$-hCG levels and cut-off values, sensitivity and specificity were determined for methotrexate success at the $1^{\text {st }}, 4^{\text {th }}$ and $7^{\text {th }}$ days.

\section{RESULTS}

A total of 462 patients who were diagnosed as ectopic pregnancy between January 2013 and December 2017 and treated with single dose methotrexate as initial treatment were included in the study. Single dose methotrexate treatment was successful in 350 (75.8\%) patients, but failed in 112 (24.2\%) patients and the second dose methotrexate or surgical treatment was applied in these patients.

Table 1 shows a comparison of the demographic and clinical characteristics of successful and unsuccessful groups. There was no significant difference between the two groups in terms of age, gravida, parity, hemoglobin and hematocrit values. Serum $\beta$-hCG values on the day of methotrexate administration, $\beta$-hCG levels at the $4^{\text {th }}$ and $7^{\text {th }}$ day and ectopic mass size were significantly higher in the unsuccessful group $(p<0.001)$. Figure 1 shows ROC analysis for methotrexate success and $\beta$-hCG levels and mass size. According to the ROC analysis, when the cut-off value of $\beta$-hCG was taken as $2.000 \mathrm{mIU} / \mathrm{mL}$ on the day of methotrexate administration, the sensitivity and specificity were $81 \%$ and $83 \%$, respectively. When the cut-off value of $\beta$-hCG was taken as 2.500 $\mathrm{mIU} / \mathrm{mL}$ at the $4^{\text {th }}$ day, sensitivity was $82 \%$, specificity was $90 \%$, and when the cut-off value of $\beta$-hCG was taken as $2.100 \mathrm{mIU} /$ $\mathrm{mL}$ at the $7^{\text {th }}$ day, sensitivity was $83 \%$, specificity was $92 \%$. When the cut-off value for ectopic mass size was calculated as $20 \mathrm{~mm}$, the sensitivity and specificity of predicting methotrexate success were $75 \%$ and $56 \%$, respectively.

Table 1. Comparison of demographic and clinical characteristics of the two groups

\begin{tabular}{|l|l|l|l|}
\hline & $\begin{array}{l}\text { Successful } \\
(\mathbf{n = 3 5 0 )}\end{array}$ & $\begin{array}{l}\text { Unsuccessful } \\
(\mathbf{n}=112)\end{array}$ & $\mathbf{p}$ \\
\hline Age & $29.97 \pm 5.62$ & $29.95 \pm 5.32$ & 0.963 \\
\hline Gravida & $2.90 \pm 1.54$ & $2.81 \pm 1.60$ & 0.593 \\
\hline Parity & $1.19 \pm 1.07$ & $1.13 \pm 1.08$ & 0.624 \\
\hline Abortus & $0.63 \pm 0.60$ & $0.58 \pm 0.52$ & 0.646 \\
\hline Gestation week & $5.88 \pm 1.71$ & $6.12 \pm 1.79$ & 0.189 \\
\hline Hemoglobin $(\mathrm{g} / \mathrm{dL})$ & $12.06 \pm 1.40$ & $12.04 \pm 1.26$ & 0.855 \\
\hline Hematocrit $(\%)$ & $36.66 \pm 3.80$ & $36.70 \pm 3.42$ & 0.913 \\
\hline$\beta$-hCG 1 $(\mathrm{mIU} / \mathrm{mL})$ & $1369.67 \pm 1013.71$ & $3876.59 \pm 3108.21$ & $<0.001$ \\
\hline$\beta$-hCG 4 $(\mathrm{mIU} / \mathrm{mL})$ & $1207.55 \pm 1157.48$ & $4292.66 \pm 2718.72$ & $<0.001$ \\
\hline$\beta$-hCG 7 $(\mathrm{mIU} / \mathrm{mL})$ & $866.70 \pm 799.39$ & $4067.01 \pm 2314.14$ & $<0.001$ \\
\hline Mass size $(\mathrm{mm})$ & $12.97 \pm 11.53$ & $23.35 \pm 13.03$ & $<0.001$ \\
\hline
\end{tabular}

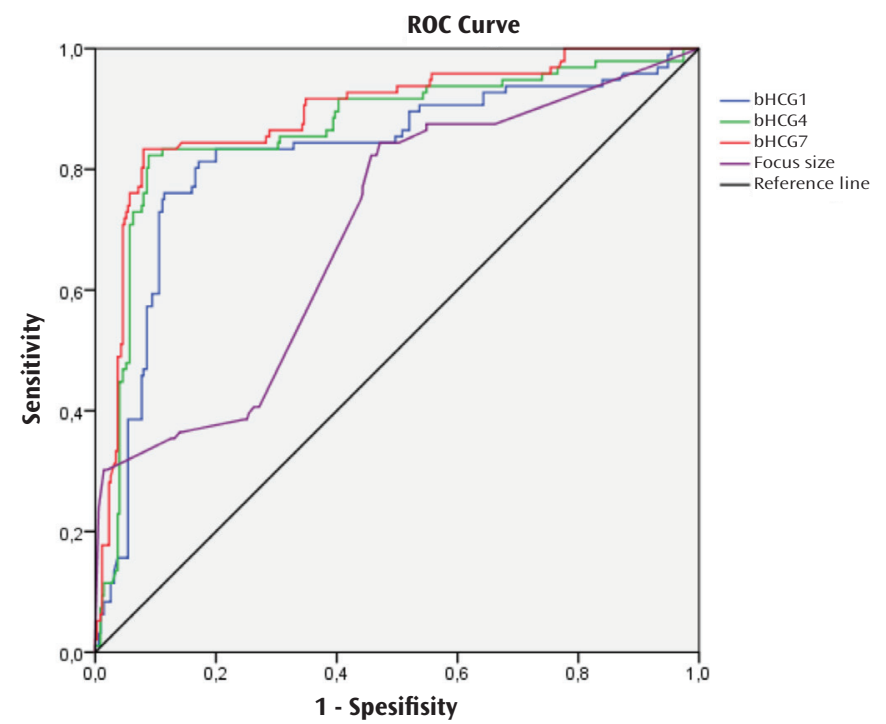

Figure 1. ROC analysis of factors influencing methotrexate success 


\section{DISCUSSION}

In the treatment of ectopic pregnancy, wait and see method, medical and surgical treatment can be applied. Which of these methods is preferred is decided by considering the clinical and laboratory findings and fertility of the patient (12). In this study, we investigated the factors that affect the success of methotrexate in patients receiving single dose methotrexate treatment. With the early diagnosis of ectopic pregnancy cases, medical treatment options have started to be developed without damaging the tubes. Methotrexate is the most successfully used medical agent for this purpose. Methotrexate is a folic acid antagonist and inhibits the formation of tetrahydrofolate required for DNA, RNA and adenosine triphosphate synthesis (13). In ectopic pregnancies, methotrexate treatment can be administered as single dose or multiple doses, local or systemic. As experiences with methotrexate have increased, single-dose regimens have emerged to simplify treatment, improve compliance, and reduce side effects and cost. Successful results have been obtained with systemic administration of single dose methotrexate (14). In this study, all patients were initially treated with a single dose methotrexate protocol. Methotrexate is used as a medical agent in the treatment of ectopic pregnancy. The success of the drug is related to the clinical and laboratory findings of the patient (15). The definite contraindications of methotrexate treatment are unstable hemodynamics, active hepatic or renal disease, and relative contraindications are $\beta$-hCG $>10.000 \mathrm{mIU} / \mathrm{mL}$ and fetal cardiac activity (16). Success rates of single dose methotrexate use range from $64 \%$ to $94 \%$ (17). Similar to the literature, the success rate was $75.8 \%$ in our study. There are limited publications on the factors that affect the success of single dose methotrexate treatment in ectopic pregnancy. While high serum $\beta$-hCG levels were found to be the only effective prognostic factor in a study (17), Kimiaei et al. (18) found that ectopic mass size, in addition to initial $\beta$-hCG level, was a factor affecting the success of the single-dose methotrexate treatment. In some studies, in addition to the high initial $\beta$-hCG level, the decrease in $\beta$-hCG levels at the $4^{\text {th }}$ day after methotrexate treatment was suggested to be the most important prognostic factor in predicting success $(19,20)$. In a study performed by Mungan et al. (21) it was shown that the location of ectopic pregnancy in tubes was important in determining the success of single dose methotrexate treatment. The success of methotrexate has been shown to be better in periampular ectopic pregnancies compared to periistmic location (21). In our study, we determined ectopic mass size and serum $\beta$-hCG levels as factors affecting success. We found that treatment success was reduced when the ectopic mass was over $20 \mathrm{~mm}$. Serum $\beta$-hCG levels are closely related to medical treatment and success rates. In the study of Lipscomb et al. (22) $\beta$-hCG levels were significantly higher in the single-dose methotrexate unsuccessful group. Lipscomb et al. (22) reported that $\beta$-hCG at the beginning of treatment was the best prognostic data for predicting methotrexate success. In their study, they determined a success rate of $94 \%$ when the initial $\beta$-hCG level was below 10.000 and $75 \%$ when it was above 10.000 . More recent publications have shown that this cut-off value is more effective between 2.000 and 3.000 (19). In our study, we found that treatment success was higher when the initial $\beta$-hCG cut-off value was below 2.000 .

\section{CONCLUSION}

In conclusion, there are many factors affecting the success of single dose methotrexate treatment in ectopic pregnancy. The most important of these are the ectopic mass size and initial B-hCG level. The patient's fertility status, clinical and laboratory findings, and serum $\beta$-hCG follow-up are important considerations in the planning of appropriate treatment.

\section{Ethics}

Ethics Committee Approval: Ethics committee approval was received for this study from the ethics committee of Sadi Konuk Training and Research Hospital (2017/414).

Informed Consent: Informed consent is not obtained due to the retrospective nature of this study.

Peer-review: External and internal peer-reviewed.

\section{Authorship Contributions}

Surgical and Medical Practices: B.A.Ç., Concept: B.A.C.., B.A.M., Design: B.A.C., B.A.M., Data Collection or Processing: B.A.Ç., Analysis or Interpretation: B.A.M., Literature Search: B.A.M., Writing: B.A.Ç.

Conflict of Interest: The authors have no conflicts of interest to declare.

Financial Disclosure: The authors declared that this study has received no financial support.

\section{REFERENCES}

1. Lozeau AM, Potter B. Diagnosis and management of ectopic pregnancy. Am Fam Physician 2005;72:1707-14.

2. Chang J, Elem-Evans LD, Berg CJ, Herndon J, Flowers L, Seed KA, et al. Pregnancy-related mortality surveillance: United States, 1991-1999. MMWR 2003;52:1-8.

3. Atasü T, Sahmay S (Eds). Jinekoloji, 2. Baski, Nobel Yayınevi, İstanbul 2001:s.547-57. 
4. Hajenius PJ, Mol F, Mol BW, Bossuyt PM, Ankum WM, Van der Veen F. Interventions for tubal ectopic pregnancy. Cochrane Database Syst Rev 2007; CD000324.

5. Stovall TG, Ling FW. Single dosemethotrexate: an expanded clinical trial. Am J Obstet Gynecol 1993;168:1759-65.

6. Kirk E, Condous G, Bourne T. The nonsurgical management of ectopic pregnancy. Ultrasound Obstet Gynecol 2006;27:91-100.

7. Fernandez H, Lelaidier C, Thouvenez V, Frydman R. The use of a pretherapeutic, predictive score to determine inclusion criteria for the nonsurgical treatment of ectopic pregnancy. Hum Reprod 1991;6:995-8.

8. Canis M, Savary D, Pouly JL, Wattiez A, Mage G. Ectopic pregnancy: criteria to decide betweenmedical and conservative surgical treatment? J Gynecol Obstet Biol Reprod 2003;32:S54-63.

9. Potter MB, Lepine LA, Jamieson DJ. Predictors of success with methotrexate treatment of tubal ectopic pregnancy at Grady Memorial Hospital. Am J Obstet Gynecol 2003;188:1192-4.

10. Nazac A, Gervaise A, Bouyer J, de Tayrac R, Capella-Allouc S, Fernandez H. Predictors of success in methotrexate treatment of women with unruptured tubal pregnancies. Ultrasound Obstet Gynecol 2003;21:181-5.

11. Dilbaz S, Caliskan E, Dilbaz B, Degirmenci O, Haberal A. Predictors of methotrexate treatment failure in ectopic pregnancy. J Reprod Med 2006;51:87-93.

12. Mol F, Mol BW, Ankum WM, van der Veen F, Hajenius PJ. Current evidence on surgery, systemic methotrexate and expectant management in the treatment of tubal ectopic pregnancy: a systematic review and meta-analysis. Hum Reprod Update 2008;14:309-19.

13. Merisio C, Anfuso S, Berretta R, Gualdi M, Pultrone D, et al. Single -dose methotrexate for Ectopic pregnancy treatment: preliminary data Acta Bio Med 2005;76:33-6.
14. Zargar M, Razi T, Barati M. Comparison of single and multidose of methotrexate in medical treatment of ectopic pregnancy. Pak J Med Sci 2008;24:586-9.

15. Gibbs R, Karlan B, Haney A. Danforth's Obstetrics and Gynecology. Baltimore: Lippincott Williams and Wilkins; 2010.

16. The Management of tubal pregnancy. Royal college of obstetricians and gynaecologists guidelines 2004;21:1-10.

17. Tawfiq A, Agameya AF, Claman P. Predictors of treatment failure for ectopic pregnancy treated with single-dose methotrexate. Fertil Steril 2000;74:87780.

18. Kimiaei P, Khani Z, Marefian A, Ghavamabadi MG, Salimnejad M. The importance of gestational sac size of ectopic pregnancy in response to single- dose methotrexate. ISRN Obstet Gynecol 2013:269425.

19. Ustunyurt E, Duran M, Coskun E, Ustunyurt ÖB, Şimşek H. Role of initial and day 4 human chorionic gonadotropin levels in predicting the outcome of single-dose methotrexate treatment in women with tubal ectopic pregnancy. Arch Gynecol Obstet 2013;288:114952.

20. Çelik E, Türkçüoğlu I, Karaer A, Kırıcı P, Eraslan S. Assessment of early decline in percentage of $\beta$-hCG values between days 0 and 4 after methotrexate therapy in ectopic pregnancy for prediction of treatment success. J Turkish German Gynecol Assoc 2013;14:1259.

21. Mungan T, Erdemoğlu E, Guney M. The impact of ultrasonographic impantation site of ectopic pregnancy on methotrexate treatment success and reproductive outcome. J Turkish-German Gynecol Assoc 2007;8:387-91.

22. Lipscomb GH, Puckett KJ, Bran D, Ling FW. Management of separation pain after single-dose methotrexate therapy for ectopic pregnancy. Obstet Gynecol 1999;93:590-3. 